\title{
Mirídeos neotropicais CCXXXVIII: Descriçōes de três especies novas do Estado do Amazonas (Hemiptera)
}

\author{
José C. M.. Carvalho $(*)$
}

\begin{abstract}
Resumo
Descrição de 3 espécies de mirídeos (Hemiptera) da região de Manaus: Platyscytus manauensis n. sp., P. das Laranjeiras: Anomalocornis ariasis n. sp., P. das Laranjeiras e Auchus schubarti n. sp., Br-174 no Km 153, Amazonas.
\end{abstract}

Este é o segundo trabalho em que o autor descreve mirídeos (Hemiptera) da região de Manaus, coligidos por colegas do Instituto $\mathrm{Na}-$ cional de Desquisas da Amazônia, especialmente por Norman D. Penny e Jorge Arias. O material tipo acha-se depositado na coleção entomológica do INPA.

A fragilidade dos exemplares não permitiu a dissecção das genitálias. Como são representantes de gêneros bem conhecidos e com número de espécies limitadas, a ilustração do holóipo servirá para caracterizar bem cada uma.

As ilustrações no texto são de autoria de Paulo Roberto Nascimento, sob supervisão do autor.

O autor deseja consignar seus agradecimentos aos colegas de Manaus que coligiram essas três interessantes espécies novas da família Miriajae.

Platyscytus manauensis $\mathrm{n} . \mathrm{sp}$.

(Fig. 1)

Caracterizada pela coloração do corpo.

Fêmea: Comprimento $2,6 \mathrm{~mm}$, largura 1,0 $\mathrm{mm}$. Cabeça: Comprimento $0,1 \mathrm{~mm}$, largura $0,4 \mathrm{~mm}$, vértice $0,24 \mathrm{~mm}$. Antena: Segmento I, comprimento $0,2 \mathrm{~mm}$; II, $0,6 \mathrm{~mm}$; III, $0,1 \mathrm{~mm}$; IV, $0,1 \mathrm{~mm}$. Pronotum: Comprimento $0,7 \mathrm{~mm}$, largura na base $0,7 \mathrm{~mm}$. Cúneo: Comprimentos 0,32 , largura na base $0,24 \mathrm{~mm}$ (holótipo) .
Coloração geral pálido-amarelada ao ocráceo com manchas avermelhadas; olhos, faixa longitudinal sobre as margins laterais do pronoto, escutelo (exceto ângulos basais), faixa transversal irreguiar no cório, ao nível da extremidade apical do clavo, manchas coalescentes de cada lado da comissura corial, extremo ápice do embolio e extremidade apical do cúneo vermelhos, faixa transversal irregular da porção sub-basal do cúneo cor de laranja ou abóbora; membrana translúcida.

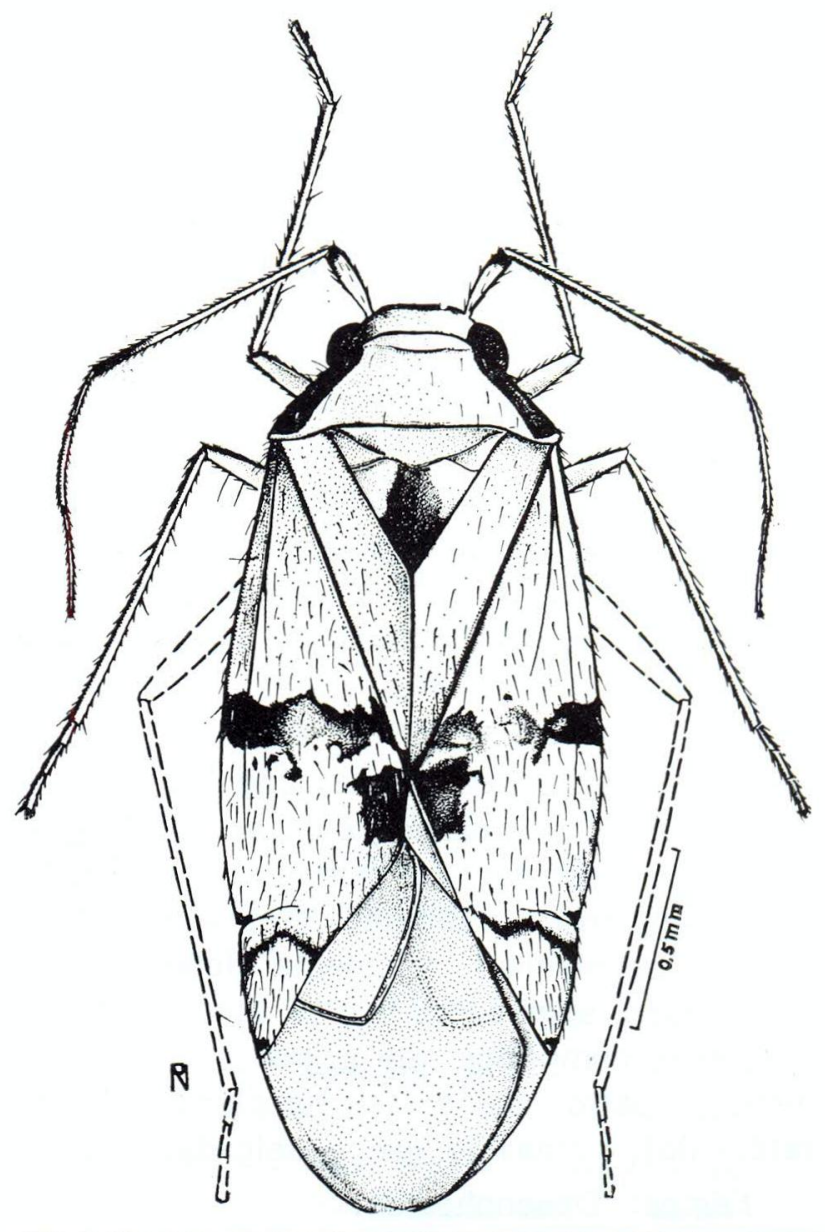

Fig. 1 - Platyscytus manauensis n. sp. fêmea, holótipo.

(") - Museu Nacional, Rio de Janeiro. Bolsista do Conselho Nacional de Desenvolvimento Científico e Tecnológico (CNPq). 
Antena com ápice dos segmentos I e II avermelhado, abdome e pernas ocráceos.

Macho: Desconhecido.

Holótipo: Fêmea, BRASIL, Amazonas, P. das Laranjeiras, 7.IX.81, Jorge Arias col., na coleção do Instituto Nacional de Pesquisas da Amazônia (INPA), Manaus.

Diferencia-se de Platyscytus rubrofasciatus Carvalho \& Gomes, 1971 pela coloração das margens do pronoto e pela faixa irregular sub basal do cúneo.

As características morfológicas da espécie são as mesmas indicadas para o gênero, apenas a pubescência mais rala.

\section{Anomalocornis ariasi $\mathrm{n} . \mathrm{sp}$.}

(Figs. 2 - 3)

Caracterizada pela coloração do corpo e pela estrutura da genitália do macho:

Macho: Comprimento $2,9 \mathrm{~mm}$, largura $0,8 \mathrm{~mm}$. Cabeça: Comprimento 0,2 mm, largura $0,6 \mathrm{~mm}$, vértice $0,28 \mathrm{~mm}$. Antena: Segmento I, comprimento $0,2 \mathrm{~mm}$; II, $0,4 \mathrm{~mm}$; III, 1,4 $\mathrm{mm}$; IV, 0,4 mm. Pronoto: Comprimento 0,4 $\mathrm{mm}$, largura na base $0,8 \mathrm{~mm}$. Cúneo: Comprimento $0,88 \mathrm{~mm}$, largura na base $0,28 \mathrm{~mm}$ (holótipo) .

Coloração geral pálido-amarelada ao citrino com áreas negras; cabeça, olhos e antenas negros, segmento II pálido-amarelado; escutelo castanho-claro, levemente mais escuro que 0 clavc. Lado inferior negro, coxas (exceto bases) e pernas pálido-amarelados.

Pubescência semierecta, ângulos anteriores do pronoto e cabeça com cerdas longas, antena com segmento II característico (fig. 3) com pêlos longos e aspecto de escova, do lado inferior, segmento I fortemente globoso, afilado na base, segmentos II e IV com pêlos longos, mais compridos que a grossura dos segmenots; rostro encoberto (exemplar colado em retênculo), pernas longas e delgadas.

Fêmea: Desconhecida.

Holótipo: Macho, BRASIL, Manaus. P. das Laranjeiras, 4.IX.81, Jorge Arias, na coleção do Instituto Nacional de Pesquisas da Amazônia (INPA), Manaus.

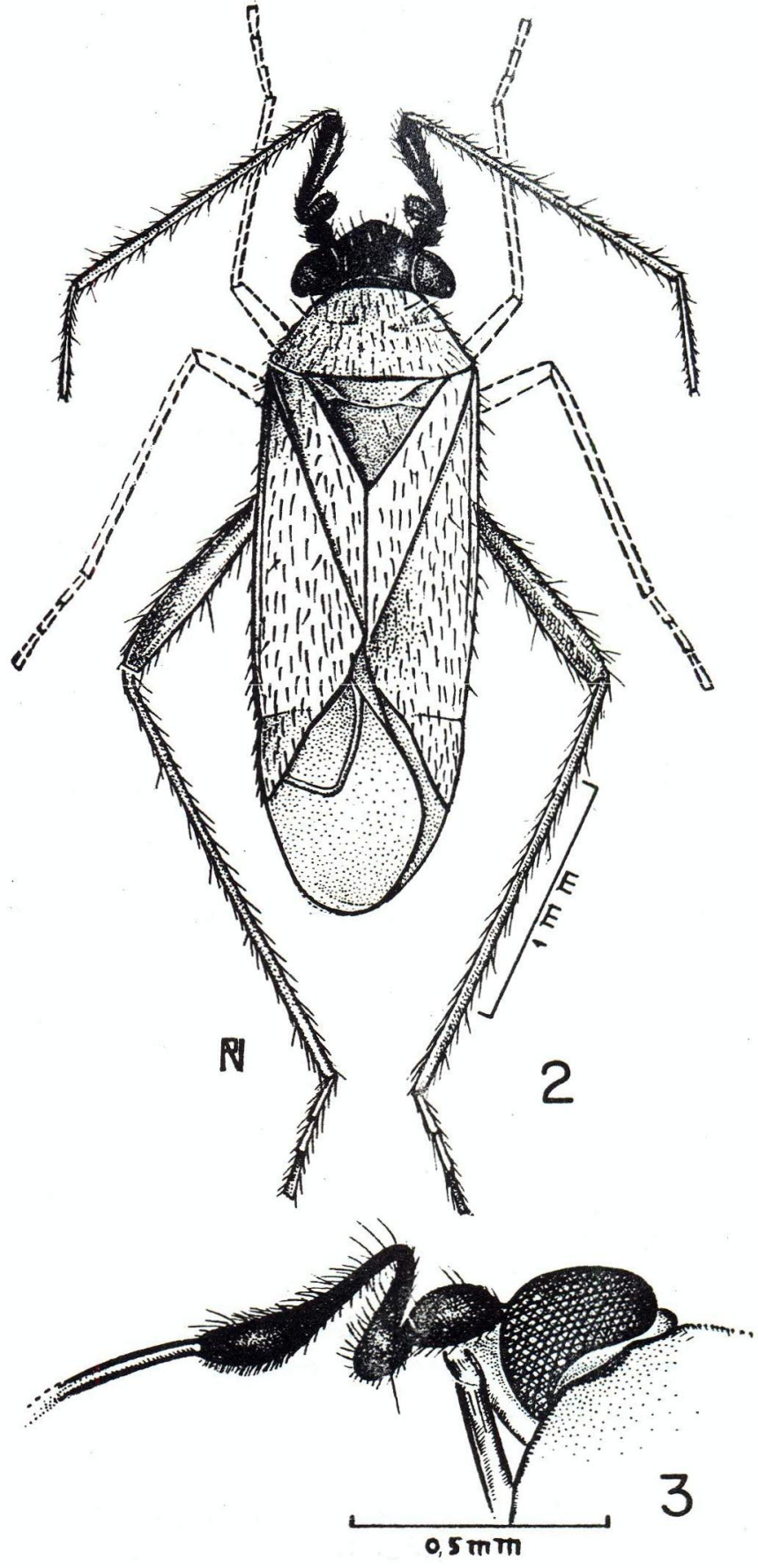

Figs. 2-3 - Anomalocornis ariasi n. sp., 2) macho, holótipo; 3) detalhe da antena vista de lado.

Difere de Anomalocornis geijskesi CarvaIho \& Wygodzinsky, 1945 pela coloração da antena e estrutura da genitália do macho.

O nome da espécie é dado em homenagem ao seu coletor Jorge Arias que reuniu uma interessante coleção de mirídeos na $P$. de Laranjeiras, nos arredores de Manaus. 


\section{Auchus schubarti n.sp.}

(Fig. 4)

Caracterizada pela forma do segundo segmento da antena do macho.

Macho: comprimento $4,4 \mathrm{~mm}$, largura 1,7 $\mathrm{mm}$. Cabeça: comprimento $0,4 \mathrm{~mm}$. largura $0,8 \mathrm{~mm}$, vértice $0,40 \mathrm{~mm}$. Antena: segmento 1 , comprimento $0,44 \mathrm{~mm}$, largura no ápice 0,40 $\mathrm{mm}$; II, $1,8 \mathrm{~mm}$, maior largura $0,48 \mathrm{~mm}$; III, $0,3 \mathrm{~mm}$; IV, $0,2 \mathrm{~mm}$. Pronoto: comprimento $1,1 \mathrm{~mm}$; largura na base $1,4 \mathrm{~mm}$. Cúneo: comprimento $0,60 \mathrm{~mm}$, largura na base $0,44 \mathrm{~mm}$ (holótipo).

Coloração geral pálido-amarelado com áreas castanhas ou avermelhadas; cabeça e

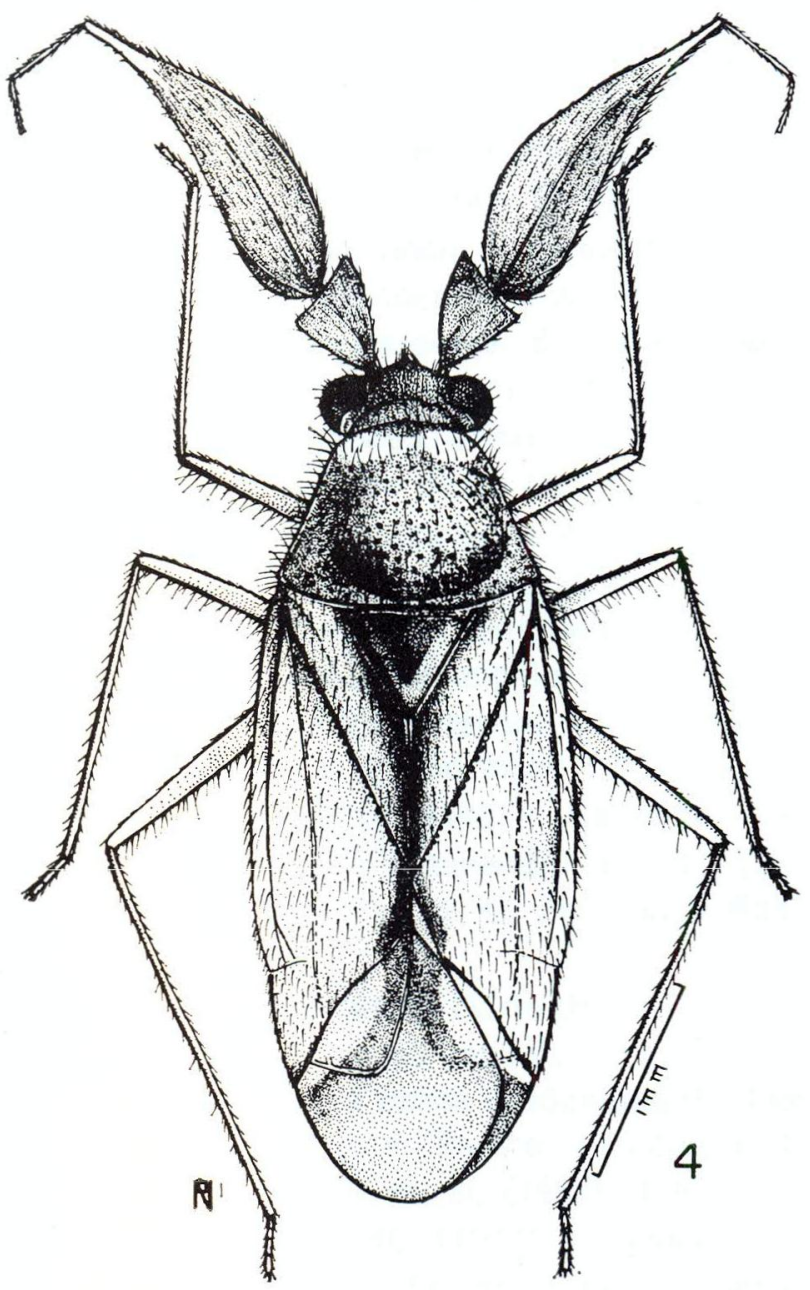

Fig. 4 - Auchus schubarti n. sp., macho, holótipo. pronoto castanho claro, área dos calos pálida, escutelo castanho com faixa triangular mais escura longitudinalmente; hemiélitros pálidoamarelados, sutura claval enegrecida, sutura embólio-corial avermelhada, commissura coria! com pequena mancha escura de cada lado, convergentes; margem apical interna do cúneo avermelhada; membrana com nervuras e mancha mediana escuras; antena com segmento I e II avermelhados, este último pálido na porção apical, segmentos III e IV castanho-avermelhados. Lado inferior castanho, ápice das coxas e pernas pálido-amareladas.

Corpo com pilosidade erecta, antena com segmentos I e II foliáceos, este último com a extremidade apical afilada, suturas cório-embolial e cório-claval com pontuações, cúneo mais longo que largo na base, membrana pilosa, translúcida.

Genitalia do tipo Hyaiiodini, perdida durante a disseção do pigóforo.

Fêmea: desconhecida.

Holótipo: macho, BRASIL: Amazonas, $\mathrm{Br}$ 174, km 153, 14.VI.1977, Norman D. Penny col., na Coleção de Entomologia do Instituto Nacional de Pesquisas da Amazônia (INPA), Manaus.

Difere das demais espécies do gênero pela forma peculiar do segmento II da antena (vide Carvalho e Knight, 1943 e Carvalho, 1974).

O nome específico é dado em homenagem ao Doutor Herbert Schubart, Diretor Adjunto do INPA em reconhecimento pela valiosa contribuição prestada a pesquisadores na Amazônia.

\section{SUMMARY}

The author describes three new species of Hemiptera, Miridae from the neighbourhood of Manaus, as follows: Platyscytus manauensis n. sp., P. das Laranjeiras; Anomalocornis ariasi n. sp., P. das Laranjeiras e Auchus schubarti n. sp., Br-174 (Highway), Km 153, Amazonas. Illustration of the three new species are included. 


\section{REFERENCIAS BIBLIOGRÁFICAS}

CARVALHO, J.C.M.

1974 - Mirídeos Neotropicais, CLXXXVII: Revisão dos Gêneros Auchus Distant e Piestotomus Bergroth (Hemiptera). In: Rev. Brasil. Biol., 34 (4): 495-504, 19 figs.

\section{CARVALHO, J.C.M. \& GOMES, I.P.}

1971 - Mirídeos Neotropicais, CXXXII: Descrição de um Gênero e três Espécies novas do Brasil. In: Rev. Brasil. Biol., 31 (2): 205-208. 7 figs.
CARVALHO, J.C.M. \& KNIGHT, H.H.

1943 - Neotropical Miridae - Two new species of Auchus Distant from Brazil (Hemiptera). In: Rev. Brasil. Biol., 3 (1): 83-85.

CARVALHO, J.C.M. \& WYGODZINSKY, P.

1945 - Mirídeos Neotropicais, XIV: A new genus and species of Phylinae from Dutch Guiana (Hemiptera). In: Rev. Brasil. Biol., 5 (1): 33-35, 7 figs.

(Aceito para publicação em 02/05/82) 